\title{
Use of natural bentonite clays in pond fish farming to create optimal concentrations of ammonium ions
}

\author{
Timur Tlupov ${ }^{1, *}$, Karina Bambetova ${ }^{2}$, Kamaludin Magomedov ${ }^{1}$, Ruslan Kumykov $^{1}$, and \\ Nikolay Khalko ${ }^{3}$ \\ ${ }^{1}$ Kabardino-Balkarian State Agricultural University named after V. M. Kokov, Lenin Avenue, 1V, \\ 360030 Nalchik, Russia \\ ${ }^{2}$ Kabardino-Balkarian State University named after Kh.M. Berbekov, Chernyshevskogo St., 173, \\ 360004 Nalchik, Russia \\ ${ }^{3}$ Grodno State Agrarian University, Tereshkova St., 28, 230008 Grodno, Republic of Belarus
}

\begin{abstract}
The composition and some sorption properties of bentonite clays, the efficiency of natural waters treatment in pond fish farming from excess ammonium ions using the natural bentonite clay from the Gerpegezhskoye deposit have been studied. The maximum sorption capacity of bentonite clay of this material has been determined. It is found out that when a smaller amount of the sample is added to each liter of the standard solution $(0.1$ and $0.01 \mathrm{~g})$, higher values of the sorption capacity are identified. To achieve the optimal degree of cleaning of ponds from excess ammonium ions and expediency in terms of reducing the material and labor costs to a minimum, the optimal amount of bentonite was calculated, the use of which would be sufficient to maintain the ammonium ion concentration. The conditions were chosen so that to ensure a decrease in the ammonium nitrogen concentration from 2-3 maximum allowable concentration (MAC) $(5-7.5 \mathrm{mg} / \mathrm{l})$ to $0.2-0.8 \mathrm{mg} / \mathrm{l}$. It is shown that the sorption capacity is realized more efficiently when the bentonite weigh decreases to $0.01 \mathrm{~g} / \mathrm{L}$, provided that the ammonium ion content in the aqueous medium exceeds the MAC by 2-3 times.
\end{abstract}

\section{Introduction}

Today, zeolites, glauconites and clay rocks are mainly used in pond fish farming to create an ecologically clean habitat [1-5]. Despite the growing market needs and the availability of wide resource base in Russia [6-8], the available range of natural compounds, the sorbents used in pond fish farming, is limited [6,7]. About $75 \%$ of the Russian pond fish farmers use natural sorbents developed over 40 years ago. The development of new effective formulations with the use of affordable and cheap natural bentonites remains relevant. In this regard, to study Gerpegezhskoye deposit of bentonite clays as sorbents (taking into account the sufficient cheapness and high sorption capacity) in pond fish farming for

\footnotetext{
*Corresponding author: timyrtlypov@mail.ru
} 
creation of the ecologically clean habitat is, in our opinion, of significant practical and scientific interest.

Their use is due to sufficiently high sorption capacity [9], ion exchange properties [910], availability and low cost [11]. The most common sorbents are clay minerals that include bentonite clays. Bentonites are included in the group of layered band aluminosilicates with expanding structure, which determines their high sorption capacity and swelling capacity [9-11]. The Gerpegezhskoye deposit bentonite clay content $\mathrm{SiO}_{2}$ $62 \%, \mathrm{Al}_{2} \mathrm{O}_{3}-13.5 \%, \mathrm{CaO}-7.8 \%, \mathrm{MgO}-2.36 \%, \mathrm{Fe}_{2} \mathrm{O}_{3}-5.3 \%, \mathrm{~K}_{2} \mathrm{O}-2.5 \%, \mathrm{Na}_{2} \mathrm{O}-$ $1.3 \%$. Bentonite clays include a large set of macro- and micronutrients being vital for the organism - $\mathrm{Cu}, \mathrm{Zn}, \mathrm{Mn}, \mathrm{Co}, \mathrm{Ag}, \mathrm{Ca}, \mathrm{Mg}, \mathrm{Cr}$, J, etc. The authors [12] found that bentonite clays showed increase in the sorption exchange capacity in the acid - salt - soda activation series. It is noted that soda activation increases the maximum value of the sorption exchange capacity by almost 3 times in comparison with the native (in the natural state) clay. The used samples were not subjected to acidic, saline and soda activation and were used in their natural state.

For the reared fish production, the high productivity is constrained by a number of important stress factors: the accumulation of gas - ammonia $\left(\mathrm{NH}_{3}\right)$ which is formed during biochemical decomposition of nitrogen-containing organic compounds when dissolved in water $[13,14]$; oxygen deficiency, that has a detrimental effect on the vital parameters of fish, can cause developmental disorders and lead to death $[15,16] ; \mathrm{pH}$ of the medium neutral $\mathrm{pH}$ is the most favorable for fish. With significant shifts in $\mathrm{pH}$ by acidic or alkaline parameter, the fish respiration rate decreases. The deterioration of the toxicological situation occurs due to the accumulation of heavy metals, pesticides, oil products in the surface waters and due to acid rains $[17,18]$. We have considered the comprehensive effect of all these factors on the state of hydrobionts and fish capacity. However, in this work, we give only the results of studies on the pond water treatment for fish farming from ammonium ions with the use of bentonites with their sorption capacity, and we assess the effectiveness of their effect on the hydrochemical and toxicological situation.

\section{Materials and Methods}

To determine the maximum capacity, the bentonite weigh fraction $0.25-0.5 \mathrm{~mm}$ was put into the $25 \mathrm{ml}$ conical flask with $5 \mathrm{ml}$ of $0.25 \mathrm{M}$ ammonium chloride solution. The sample was saturated with ammonium for 6,8 and 10 hours and subject to mechanical stirring. Then the solid phase was separated by filtration and aliquot $(0.5 \mathrm{ml})$ was taken to determine the ammonium ion content with the Nessler's reagent [18]. The $5 \mathrm{~g}$ sample weigh was put into the $250 \mathrm{ml}$ flask with $50 \mathrm{ml}$ of $0.25 \mathrm{M}$ ammonium chloride solution. The saturation with ammonium was performed for 6,8 and 10 hours and subject to mechanical stirring. Then the solid phase was separated by centrifugation. The solution was analyzed for ammonium, potassium, sodium, calcium and magnesium ion content. Simultaneously, a blank experiment was carried out to make a correction for possible ingress of the same ions into the solution due to the material dissolution. In the blank experiment, the same bentonite weigh $(5 \mathrm{~g})$ was poured into $50 \mathrm{ml}$ of bidistilled water, mechanical stirring was performed during the corresponding experiment. After centrifugation, the potassium, sodium, calcium and magnesium contents were determined in the solution. Bentonite fraction $0.25-0.5 \mathrm{~mm}$ was added to the standard solution at the rate of $20 ; 10 ; 1 ; 0.1 ; 0.01 \mathrm{~g}$ of bentonite per 1 liter of the solution. The comparison of the treatment efficiency with different amounts of bentonites was carried out at a sorption time of 2, 6, 24, 72, 96, 264 hours.

The ammonium ion content was determined by the colorimetric method with the Nessler's reagent [18]. The iodometric method was used to determine the dissolved oxygen 
$[19,20]$. The hydrogen ion concentration was determined by the electrometric method [20, 21]. The calcium and magnesium exchangeable cation content was determined trilonometri cally [22], and the alkali metals, potassium and sodium cation content - by the flame photometry $[23,24]$. To determine the hydrochemical parameters, the following devices were used: colorimeter photo-electric KFK-2, pH-ion meter EV-74, analytical balance, atomic absorption spectrophotometer AAS-30.

\section{Results and Discussion}

To determine the maximum sorption capacity, weighing of the tested montmorillonite clay was carried out according to the method [18]. It is found out that when a smaller amount of the sample is added to each liter of the standard solution $(0.1$ and $0.01 \mathrm{~g})$, higher values of the sorption capacity are received (Table 1). The experiment was carried out in the fishery pond simulating conditions, the initial ammonium ion concentration in the solution corresponded to $6.3 \mathrm{mg} \cdot \mathrm{eq}$. N/1

Table 1. Bentonite capacity in the fishery pond simulating conditions, mg.eq. N/l.

\begin{tabular}{|c|c|c|c|c|}
\hline $\begin{array}{c}\text { Amount of } \\
\text { bentonite } \\
\text { per 1 liter } \\
\text { of solution, } \\
\mathrm{g}\end{array}$ & 2 & 4 & 24 & 72 \\
\cline { 2 - 5 } & 1.02 & 1.23 & 1.88 & 1.43 \\
\hline 0.1 & 11.98 & 14.76 & 15.97 & 12.94 \\
\hline 0.01 & \multicolumn{4}{|c|}{ Sorption time, h } \\
\hline
\end{tabular}

As it can be seen from Table 1, the maximum amount of ammonium ions absorbed by bentonite clay made $13.9 \mathrm{mg}$ eq. N/1 per each gram of bentonite introduced. This bentonite capacity value exceeds the theoretically possible ion-exchange bentonite capacity calculated for the tetrahedral aluminum content in its structure. The sorption process seems to include not only the exchange process on the montmorillonite, but also processes not associated with ion exchange both on the montmorillonite and on other minerals that make up the rock.

Thus, the exchange capacity value obtained in the standard test conditions averaged $0.59 \mathrm{mg}$ eq. $\mathrm{N} / 1$ of bentonite clay. The maximum amount of absorbed ammonium ions in the conditions corresponding to fish-farming ponds when $0.01 \mathrm{~g}$ of the rock was added to each liter of ammonium ion solution made $13.9 \mathrm{mg}$ eq. N/1 per each gram of montmorillonite clay.

Since the use of bentonites in the aquatic environment is based on the cation exchange, we have established which ions and in what quantity are released from bentonite during the ammonium ion sorption. The ion exchange was carried out according to the standard method for the $0.25 \mathrm{M}$ ammonium chloride solution, both by stirring and in the steady-state conditions for $6,10,12$ and 36 hours. Upon expiration of this period of time, the amount of calcium, magnesium, sodium and potassium cations and the amount of absorbed ammonium ions were determined by the difference in its concentration in the solution before and after sorption. The study results are given in Table 2.

Table 2. The composition of bentonite exchange cations released during ammonium ion exchange.

\begin{tabular}{|c|c|c|c|c|c|c|c|c|c|c|}
\hline \multirow{3}{*}{$\begin{array}{l}\text { Sorption } \\
\text { time, } \mathrm{h}\end{array}$} & \multicolumn{6}{|c|}{ Amount of exchange cation, mg.eq N/g } & \multirow{2}{*}{\multicolumn{4}{|c|}{$\begin{array}{l}\text { Equivalent composition of } \\
\text { exchange cations, } \%\end{array}$}} \\
\hline & \multicolumn{5}{|c|}{ Released } & \multirow{2}{*}{$\frac{\text { Absorbed }}{\mathrm{NH}_{4}^{+}}$} & & & & \\
\hline & $\mathrm{Ca}^{2+}$ & $\mathrm{Mg}^{2+}$ & $\mathrm{Na}^{+}$ & $\mathrm{K}^{+}$ & Eions & & $\mathrm{Ca}^{2+}$ & $\mathrm{Mg}^{2+}$ & $\mathrm{Na}^{+}$ & $\mathrm{K}^{+}$ \\
\hline 6 & 0.27 & 0.01 & 0.20 & 0.10 & 0.58 & 0.60 & 44.6 & 4.7 & 33.1 & 16.9 \\
\hline
\end{tabular}


Table 2. Continued.

\begin{tabular}{|c|c|c|c|c|c|c|c|c|c|c|}
\hline 10 & 0.36 & 0.01 & 0.19 & 0.10 & 0.66 & 0.59 & 52.3 & 3.3 & 29.1 & 14.5 \\
\hline 12 & 0.33 & 0.02 & 0.18 & 0.10 & 0.63 & 0.63 & 49.2 & 5.7 & 29.0 & 15.3 \\
\hline 36 & 0.46 & 0.02 & 0.20 & 0.09 & 0.77 & 0.79 & 57.4 & 4.4 & 25.9 & 11.5 \\
\hline
\end{tabular}

Table 2 shows that the sum of exchange cations is equivalent to the amount of absorbed ammonium ions during 36 hours of sorption. This evidences that, in the experimental conditions, the sorption process proceeds by the mechanism of ion exchange. The calcium ion is most actively exchanged for the ammonium ion. After 36 hours of sorption, each gram of bentonite released $0.46 \mathrm{mg}$ eq. of $\mathrm{Ca}^{2+}$ (or $9.2 \mathrm{mg}$ ) to the external solution that is $0.92 \%$ of the mass of the bentonite weigh and about $59.7 \%$ of the sum of all exchange cations. Thus, the research data allow us to state that in the process of ion exchange, the calcium ions mainly enter the aqueous medium in contrast to the magnesium, sodium and potassium ions. All these prevent the creation of favorable conditions for the development of hydrobionts.

To achieve the optimal degree of cleaning of ponds from excess ammonium ions and expediency in terms of reducing the material and labor costs to a minimum, the optimal amount of bentonite was calculated, the use of which would be sufficient to maintain the ammonium ion concentration. Taking into account that, on the one hand, exceeding a certain level of ammonium ion content in the pond water can cause toxic damage to hydrobionts, fish-farming standards establish the maximum allowable concentration (MAC) of ammonium ions up to $2.5 \mathrm{mg} \mathrm{N} / \mathrm{L}$. On the other hand, the presence of certain amount of ammonium ions in the water reservoirs is necessary for development of phytoplankton. The optimal concentrations of ammonium nitrogen are within the range of $0.2-0.8 \mathrm{mg} / \mathrm{l}$. Based on the above, the conditions were selected so that to ensure a decrease in the ammonium nitrogen concentration from 2-3 MAC $(5-7.5 \mathrm{mg} / \mathrm{l})$ to $0.2-0.8 \mathrm{mg} / \mathrm{l}$, and the concentrations less than $0.2 \mathrm{mg} / \mathrm{l}$ are undesirable. The bentonite weigh fraction $0.25-0.5 \mathrm{~mm}$ varied from 20 to $0.01 \mathrm{~g}$ per liter of ammonium ion solution. The experiment time ranged from 2 hours to 528 hours ( 22 days). The results of the experiment are given in Table 3 and Figure 1.

Table 3. Dependence of the bentonite sorption capacity on its amount and sorption time.

\begin{tabular}{|c|c|c|c|c|c|c|c|}
\hline $\begin{array}{c}\text { Amount } \\
\text { of } \\
\text { bentonite } \\
\text { per 1 } \\
\text { liter of } \\
\text { solution, } \\
\mathrm{g}\end{array}$ & 2 & 4 & 12 & 24 & 456 & 480 & 528 \\
\hline 20.00 & 0.011 & 0.013 & 0.015 & 0.017 & 0.021 & 0.022 & 0.022 \\
\hline 10.00 & 0.013 & 0.011 & 0.223 & 0.033 & 0.031 & 0.036 & 0.039 \\
\hline 1.00 & 0.120 & 0.250 & 0.287 & 0.305 & 0.217 & 0.274 & 0.332 \\
\hline 0.10 & 1.021 & 1.203 & 1.527 & 1.890 & 0.934 & 0.879 & 0.816 \\
\hline 0.01 & 11.980 & 14.025 & 15.125 & 15.990 & 6.928 & 7.896 & 8.427 \\
\hline
\end{tabular}

The analysis of the tested bentonite sorption capacity showed that the efficiency of the maximum capacity depends inversely on the amount of the introduced rock. When the reduced amount of bentonite 20 to $0.01 \mathrm{~g} / \mathrm{l}$ is introduced into the solution, its capacity increases during the first day by about 1000 times and then by about 300 times. 


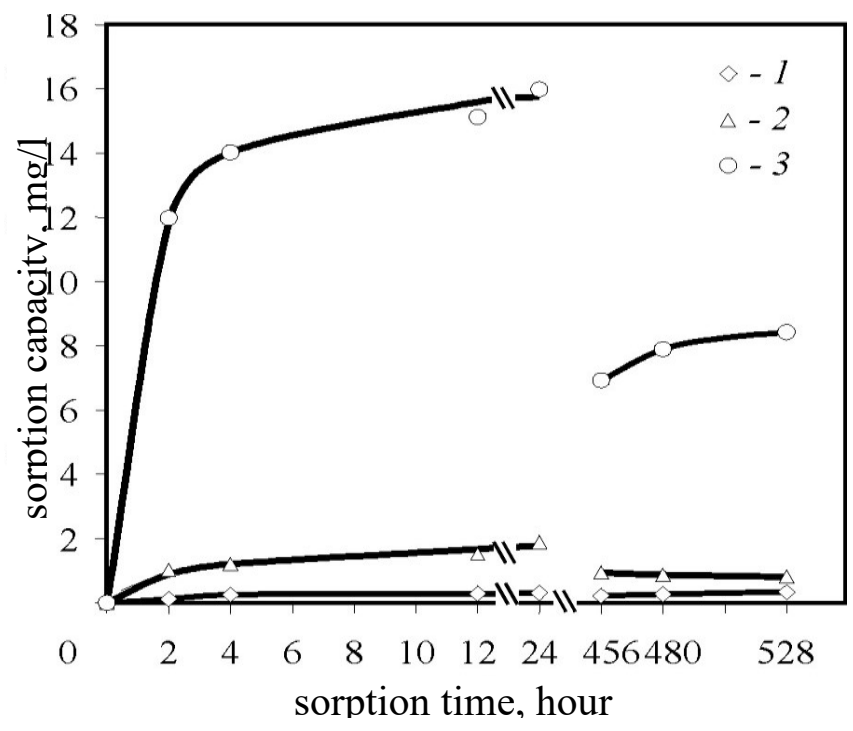

Fig. 1. Time dependence of the bentonite sorption capacity with bentonite content of, g/l: 1.00 (1); 0.10 (2) and $0.01(3)$.

Along with the determination of the bentonite sorption capacity in the same conditions, their ability to sorb ammonium ions was studied. For this purpose, the degree of ammonium ion sorption by bentonites in the amount from 0.01 to $20 \mathrm{~g} / 1$ was studied in the solutions with 3 MAC for a certain period of time. The study results are given in Table 4 and Figure 2 .

Table 4. Dependence of the ammonium ion content in the solution on the amount of bentonite, $\mathrm{mg}$ $\mathrm{N} / 1$.

\begin{tabular}{|c|c|c|c|c|c|c|c|c|}
\hline $\begin{array}{c}\text { Amount } \\
\text { of } \\
\text { bentonite } \\
\text { per 1 } \\
\text { liter of } \\
\text { solution, } \\
\mathrm{g}\end{array}$ & 0 & 2 & 4 & 24 & 72 & 456 & 504 & 528 \\
\hline 20.00 & 6.970 & 3.704 & 3.092 & 2.156 & 1.623 & 0.515 & 0.501 & 0.560 \\
\hline 10.00 & 6.621 & 4.759 & 4.615 & 1.510 & 1.510 & 1.031 & 0.960 & 0.740 \\
\hline 1.00 & 7.069 & 5.187 & 3.590 & 3.058 & 2.384 & 2.490 & 2.436 & 2.390 \\
\hline 0.10 & 6.250 & 4.460 & 4.175 & 3.263 & 3.880 & 4.797 & 4.986 & 5.024 \\
\hline 0.01 & 6.256 & 4.449 & 4.145 & 3.880 & 4.317 & 4.289 & 4.653 & 5.075 \\
\hline
\end{tabular}

Table 4 shows that after 2 hours, the ammonium ion concentration in the solutions decreases to $2 \mathrm{MAC}$ in the presence of 1 and $10 \mathrm{~g} / \mathrm{l}$ of bentonite, to $1.8 \mathrm{MAC}-0.01$ and 0.1 $\mathrm{g} / \mathrm{l}$ and to $1.56 \mathrm{MPC} 20 \mathrm{~g} / \mathrm{l}$. 


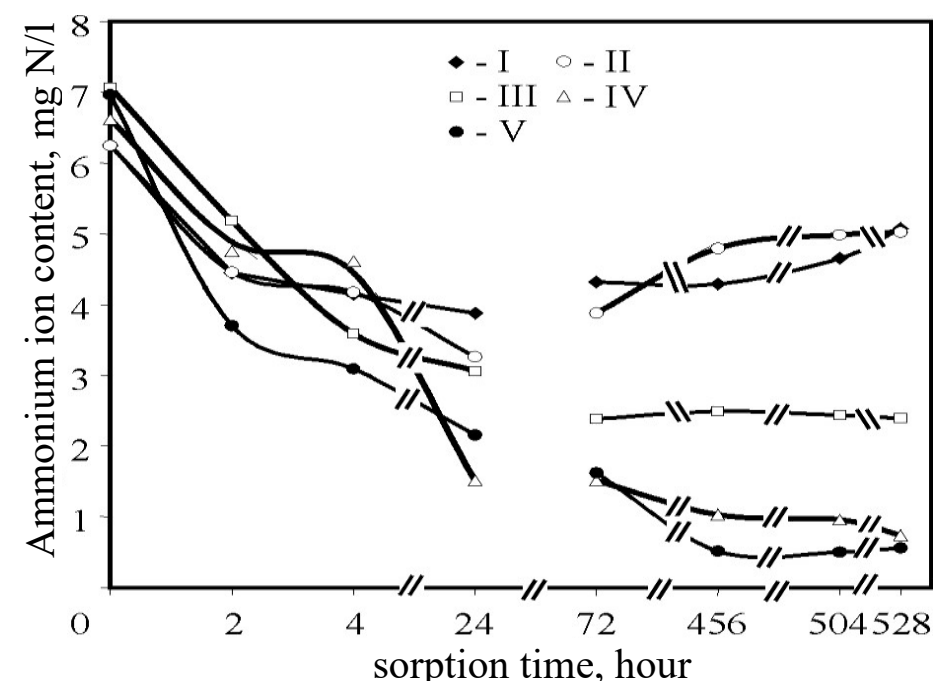

Fig. 2. Dependence of the ammonium ion concentration in the solution on the sorption time. Bentonite content, g/l: 20.00 (I); 10.00 (II); 1.00 (III); 0.10 (IV); 0.01 (V).

It follows that the 2000-times difference in the maximum and minimum amounts of the sorbent ensures the difference in the degree of ion concentration only by 0.24 MAC. It should be noted that the same trend is observed after 4 hours and after a day, and so on. This natural process creates the conditions for further decrease of the ammonium ion concentration to the optimal value. Some fluctuations in the process of sorption shown by curves 1-5 in Fig. 2 are explained by the complexity of sorption processes.

\section{Conclusion}

Taking into account such factors as time, degree of treatment of the aquatic medium, amount of sorbent, its cost and labor costs, the amount of bentonite of $0.01 \mathrm{~g} / \mathrm{l}$ is the most appropriate for reducing the ammonium ion content from $3 \mathrm{MAC}$ to the safe level.

\section{References}

1. M. W. Deem, R. Pophale, P. A. Cheeseman, D. J. Earl. J. Phys. Chem. C., 113(51) (2009)

2. S. Baerlocher, L. V. McCusker, D. H. Olson, Atlas of Zeolite Framework Types (2007)

3. V. A. Drits, A. G. Kossovskaya, Clay minerals, smectites, mixed-layer formations (1990)

4. A. I. Shevelev, Exploration and protection of mineral resources, 9, 15-19 (2005)

5. F. Ayari, E. Srasra, M. Trabelsi-Ayadi, Desalination, 185 (1-3), 391-397(2005)

6. A. Salem., L. Karimi, Korean J. of Chemical Engineering, 26 (4), 980-984 (2009)

7. L. V. Kurtukova, Success of the modern natural science, 12, 27-34 (2011)

8. V. P. Finevich, Russian Chemical J., 4, 69-76 (2007)

9. O. V. Chistik, Ecology (2000)

10. I. M. Potravny, Environmental audit, Theory and practice: Training book (2013)

11. L. M. Chukhlebova, Regional problems, 1, 54-58 (2011) 
12. A. S. Cherkasov, V. A. Somin, L.F. Komarova, L.V. Kurtukova, Success of the modern natural science, 12, 34-38 (2011)

13. N. V. Shekhovtseva, Ecology of aquatic microorganisms (2008)

14. N. G. Nalivayko. Water microbiology (2006)

15. O. N. Bauer, V. A. Musselius, V. M. Nikolaeva, Yu. A. Strelkov, Pond fish diseases, 320 (1981)

16. L. I. Grishchenko, M. Sh. Akbaev, G. V. Vasilkov, Fish diseases and fundamentals of fish-farming (1999)

17. D. A. Serov, E. V. Ryabukhina, Influence of heavy metals on hydrobionts in the ecosystem of water bodies (2013)

18. Instruction of the Scientific Board on Analytical Methods No. 235 Thermochemical quantification of pegasin in rocks (1987)

19. S. A. Alekhin, Guideline for chemical analysis of inland waters (1973)

20. Guideline RD, Volume concentration of dissolved oxygen in seawaters, Measurement by iodometric method (2010)

21. Guideline RD, for methods of chemical analysis of seawaters (2010)

22. Guideline for chemical analysis of inland surface waters (2010)

23. A. F. Zhukov, I. F. Kolosova, V.V. Kuznetsov, Analytical chemistry, Physical and physicochemical methods of analysis (2001)

24. E. M. Kats, N. K. Galkina, I. B. Serova, Geochemistry, 11, 17-22, (2011) 